\title{
ChemComm
}

\section{Outer-sphere anion recognition by a cyclen-based octadentate europium(III) complex: pH dependent recognition of ortho-phthalic acid $\dagger$}

50, 1582

Received 12th November 2013

Accepted 13th December 2013

DOI: $10.1039 / c 3 c c 48628 a$

www.rsc.org/chemcomm
Desigan Sannasy, Helder M. Marques, Manuel A. Fernandes and Alvaro S. de Sousa*
An octadentate cyclen-based europium complex with amidic and hydroxyalkyl pendent moieties exhibits $\mathrm{pH}$ dependent ligand denticity associated with anion recognition. Unusually high hydration numbers are determined for ortho-phthalate ternary outer-sphere complexes for which modulation of lanthanide-based luminescence is observed.

The design of chelating anion sensors using cyclen-based europium complexes has focussed upon heptadentate cyclen chelates bearing three pendent side-arms. In these complexes the europium squareantiprismatic coordination polyhedron includes two aqua ligands. Anion recognition events require selective displacement of aqua ligands upon binding of the anion to the metal centre. Biologically relevant dicarboxylate anions form five- or six-membered chelate rings upon binding to the metal centre with concomitant modulation of sensitised lanthanide emission. ${ }^{1}$ However, recognition of aromatic carboxylate anions is reported to be more effective using terbium(III) analogues. ${ }^{2}$

Enhanced luminescence has been observed upon binding of the $\mathrm{N}, \mathrm{N}$-dimethylaminocarboxylate anion to a heptadentate cationic terbium(III) complex at physiological $\mathrm{pH}^{2}$ The aromatic carboxylate acts as a sensitising antenna capable of adequately populating the ${ }^{5} \mathrm{D}_{4} \mathrm{~Tb}$ (III) excited state of the ternary complex, while simultaneously displacing coordinated water molecules that quench the lanthanide emission, thereby signalling the presence of the anion. Hydration states determined using a Horrocks-based method, ${ }^{3}$ endorse bidentate carboxylate binding to form fourmembered chelate rings, displacing inner-sphere water molecules. Consequently, sensing of aliphatic and aromatic dicarboxylates was further investigated using dinuclear terbium complexes. ${ }^{3}$ Dinuclear complexes encapsulated terbium(III) ions within a cyclen macrocycle bearing three pendent amide moieties, covalently linked via a $p$-xylyl spacer aimed at accommodating the binding requirements

Molecular Sciences Institute, School of Chemistry, University of the Witwatersrand, P. O. Wits, Johannesburg, 2050 South Africa.E-mail: alvaro.desousa@wits.ac.za; Fax: +27 11717 6749; Tel: +27 117176710

$\dagger$ Electronic supplementary information (ESI) available. CCDC 949567 and 949568. For ESI and crystallographic data in CIF or other electronic format see DOI: $10.1039 / \mathrm{c} 3 \mathrm{cc} 48628 \mathrm{a}$ of the dicarboxylate anions. Each metal centre was shown to independently bind a $N, N$-dimethylaminocarboxylate anion in dinuclear ternary complexes with 2:1 stoichiometry. A 1:1 stoichiometry was observed for the luminescent ternary complex of terephthalic acid in which carboxylate moieties bind to separate metal centres forming four-membered chelate rings. A number of phthalate derivatives have been identified as metabolic and endocrine disruptors, capable of inducing hormone imbalance in humans with highly toxic effects. ${ }^{4-9}$ Recognition of aromatic dicarboxylates is therefore desirable in biological and aqueous media. Hexaazamacrocyclic ligands consisting of amines linked by p-xylyl spacers and alkyl groups are reported to afford discriminatory recognition of phthalate isomers. ${ }^{10}$ Potentiometrically determined formation constants for phthalate ternary complexes with hexaazamacrocycles containing propylene groups, indicate recognition of the isophthalate complex is thermodynamically preferred. Inappropriate geometries of the ortho and para isomers inhibit optimal $\mathrm{N}-\mathrm{H} \cdots \mathrm{O}$ and $\mathrm{C}-\mathrm{H} \cdots \mathrm{O}$ hydrogen-bonding interactions with the terephthalate (para) complex exhibiting the weakest binding.

Europium(III) complexes of coordinatively saturated cyclenbased ligands, bearing four pendent side-arms, have been thoroughly scrutinised; their coordination polyhedra inevitably include a singular axially bound aqua ligand undergoing dissociative exchange with bulk water. The aqua ligand is, however, not readily substituted in aqueous media ${ }^{11,12}$ and anion sensing strategies infrequently consider octadentate europium(III) complexes. Unsaturated coordination has recently been reported for octadentate europium(III) complexes in which a brachial moiety is not bound to the metal centre. ${ }^{13,14}$ A pendent azaxanthanone group of a protein-bound octadentate europium(III) complex is reported to reside in the apolar binding cavity of the alpha-1glycoprotein and is not coordinated to the metal centre. ${ }^{13} \mathrm{~A}$ change in ligand denticity may also be advanced for preferential citrate recognition by $\mathrm{Eu}(S$-THP $)\left(\mathrm{H}_{2} \mathrm{O}\right)$, a cyclen-based octadentate europium(III) complex bearing four brachial hydroxypropyl moieties. ${ }^{14}$ Displacement of the weaker hydroxyalkyl donors, in addition to the axially coordinated water molecule, facilitates 
a multidentate chelating mode for the ternary citrate complex exhibiting enhanced emission upon direct excitation.

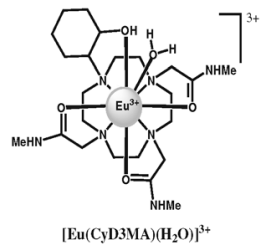

In this work a mixed donor cyclen-based europium(III) complex is shown to exhibit fluxional ligand denticity upon phthalate recognition. The formation of a ternary ortho-phthalate complex is investigated by monitoring $\mathrm{pH}$-dependent modulation of the characteristic europium(III) emission. Emission spectra were recorded for $\mathrm{pH}$ titrations in aqueous and buffered media, using biologically suited buffers ( $1 \mathrm{mM}$ MOPS, $1 \mathrm{mM}$ MES, $2.4 \mathrm{mM}$ Tris, $1 \mathrm{mM} \mathrm{KHP}$ ), at constant ionic strength. Hydration states, at relevant $\mathrm{pH}$ values are determined using a modified Horrocks method $^{15,16}$ to account for quenching contributions of the hydroxycycloalkyl and methylethanamide pendents.

Endo conformations, resembling conformations in the structure of DTMA,${ }^{17} \ddagger$ prevail for trans methylethanamide and the hydroxycycloalkyl pendents (ESI; $\dagger$ Fig. S1). The hydroxycycloalkyl pendent accommodates $\mathrm{O}-\mathrm{H} \cdots \mathrm{O}$ hydrogen-bonding to a lattice water molecule separated from the macrocyclic $\mathrm{N}_{4}$ centroid by 4.45(1) A (ESI; $\dagger$ Fig. S2 and Table S4). Outer-sphere water molecules, at comparable distances from the metal centre in cyclen-based europium(III) complexes, modestly quench (approximately 8\% efficiency) lanthanide emission, ${ }^{18}$ suggesting $\mathrm{O}-\mathrm{H} \cdots \mathrm{O}$ hydrogen bonding between the hydroxycyclohexyl pendent and proximal water molecules may only marginally influence lanthanide emission of the $[\mathrm{Eu}(\mathrm{CyD} 3 \mathrm{MA})]^{3+}$ complex in aqueous solution. $\S$

First order luminescence decay in $\mathrm{H}_{2} \mathrm{O}$ and $\mathrm{D}_{2} \mathrm{O}$ indicates a single water molecule $(q \sim 1)$ is bound to the metal centre in the $[\mathrm{Eu}(\mathrm{CyD} 3 \mathrm{MA})]^{3+}$ complex (ESI, $\dagger$ Table S1) at low $\mathrm{pH}$.

The capped square-antiprism coordination geometry observed for the $\left[\mathrm{Eu}(\mathrm{CyD} 3 \mathrm{MA})\left(\mathrm{CF}_{3} \mathrm{SO}_{3}\right)\right]^{2+}$ complex, as determined by single crystal X-ray crystallography (Fig. 1; ESI, $\dagger$ Table S5), shows a triflato ligand replacing the apically coordinated water molecule in the solid state. The $\mathrm{Eu}-\mathrm{O}_{3} \mathrm{SCF}_{3}$ distance (2.443(1) $\AA$; ESI, $\dagger$ Table S2) compares favourably with the average axial $\mathrm{Eu}-\mathrm{O}$ distance $(2.442 \AA)$ of coordinated water molecules in monoaqua, nine-coordinate europium complexes. ${ }^{18}$ Weaker hydroxycycloalkyl coordination (Eu-O distance 2.408(1) Å), compared to amidic counterparts (Fig. 1; ESI, $\uparrow$ Table S2), accommodates the apical metal-triflate interaction sterically unaffected by the brachial hydroxycyclohexyl moiety.

At elevated $\mathrm{pH}$ modulation of the europium(III) emission (detector PMT accelerator voltage $800 \mathrm{~V}$ ) coincides with a decrease in the value of $q(\sim 0.5)$ for $[\mathrm{Eu}(\mathrm{CyD} 3 \mathrm{MA})(\mathrm{OH})]^{2+}$ that signals deprotonation of the aqua ligand $\left(\mathrm{p} K_{\mathrm{a}}=8.7 \pm 0.1\right.$; ESI, $\dagger$ Fig. S3 and S4). 9 The $\mathrm{p} K_{\mathrm{a}}$ deviates significantly from that observed for $[\operatorname{Eu}(\mathrm{DTMA})(\mathrm{OH})]^{2+}\left(\mathrm{p} K_{\mathrm{a}}=7.3\right) ;^{19}$ this is attributed to hydrogen-bonding interactions involving the hydroxycyclohexyl pendent and/or outer-sphere water molecules alluded to earlier.

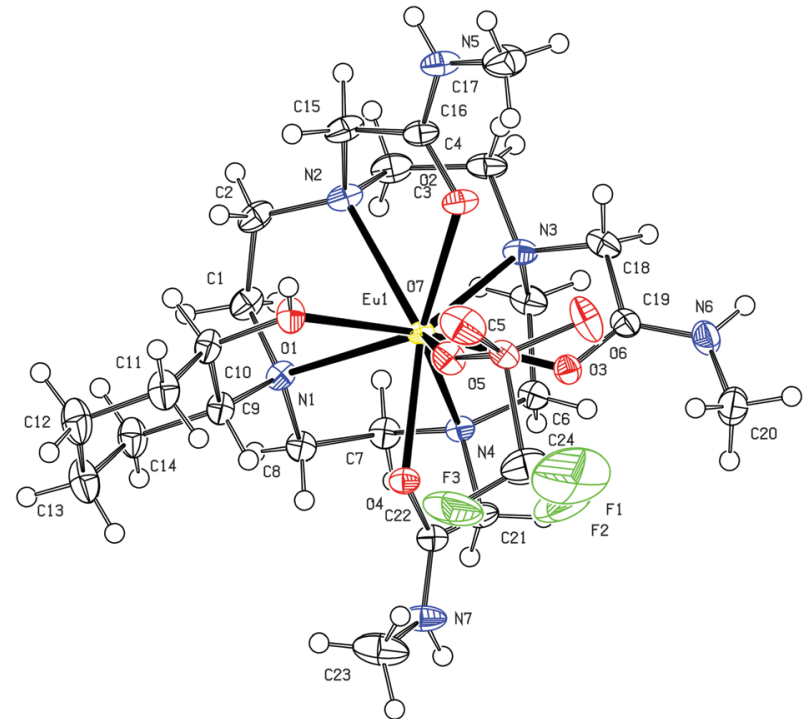

Fig. 1 Ortep diagram of $\left[\mathrm{Eu}(\mathrm{CyD} 3 \mathrm{MA})\left(\mathrm{CF}_{3} \mathrm{SO}_{3}\right)\right]^{2+}$. Thermal ellipsoids are shown at the $50 \%$ probability level.

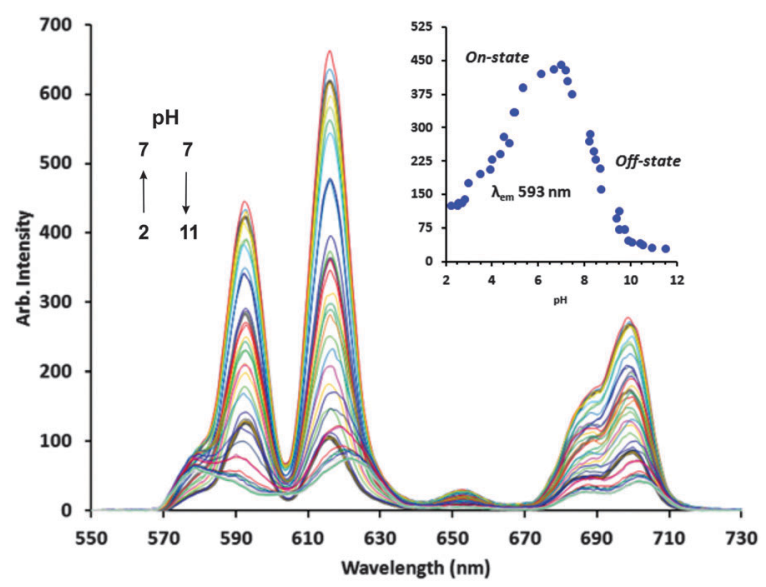

Fig. $2 \mathrm{pH}$ dependent emission spectra of Eu(III)-1,4,7-tris[( $N$-methylcarbamyl)methyll-10-(2-hydroxy-cyclohexyl)-1,4,7,10-tetraazacyclododecane $\left[\mathrm{Eu}(\mathrm{CyD} 3 \mathrm{MA})\left(\mathrm{H}_{2} \mathrm{O}\right)\right]^{3+}$ in buffered solution (KHP, MOPS, MES and TRIS). Insert: $\mathrm{pH}$ dependent emission modulation of the ${ }^{5} \mathrm{D}_{0}-{ }^{7} \mathrm{~F}_{1}$ transition.

Changes in hydration state (ESI, $\uparrow$ Table S3), with concomitant pH dependent modulation of Eu(III) emission (Fig. 2 and Fig. S5, $\mathrm{ESI} \dagger$ ), are likewise observed for a multicomponent buffer solution (KHP, MOPS, MES and TRIS) of [Eu(CyD3MA) $]^{3+}$. The spectroscopic signature for the buffered [Eu(CyD3MA $)]^{3+}$ solution is influenced by the formation of an ortho-phthalate ternary complex with unusually high values of $q$ for an octadentate europium(III) complex below physiological pH (ESI, $\uparrow$ Table S3). Hydration states at lower $\mathrm{pH}$ support ligand heptadenticity upon formation of an outersphere $\left[\mathrm{Eu}(\mathrm{CyD} 3 \mathrm{MA})\left(\mathrm{H}_{2} \mathrm{O}\right)_{2}\right]^{3+} \mathrm{pht}^{2-}$ ternary complex, in which $\mathrm{O}_{4}$ equatorial binding of the hydroxycyclohexyl pendent is replaced by a second bound water molecule. $\mathrm{p} K_{\mathrm{a}}$ values of $4.7 \pm 0.1$ and $8.7 \pm 0.1$ are determined by non-linear regression analysis of luminescent data. Electronic absorption data $\left(\pi-\pi^{*}\right.$ transition, $280 \mathrm{~nm} ; \mathrm{p} K_{\mathrm{a} 1}=2.8 \pm 0.2, \mathrm{p} K_{\mathrm{a} 2}=5.1 \pm 0.1$ ) confirms complete ortho-phthalate deprotonation in the ternary complex 
$\left[\mathrm{Eu}(\mathrm{CyD} 3 \mathrm{MA})\left(\mathrm{H}_{2} \mathrm{O}\right)_{2}\right]^{3+} \mathrm{pht}^{2-}$ (ESI, $\dagger$ Fig. S6 and S7). O-H $\cdots \mathrm{O}_{\text {pht }}$ hydrogen-bonding interactions with inner-sphere water molecules and the uncoordinated hydroxycyclohexyl pendent ${ }^{20}$ facilitate outer-sphere phthalate binding with subsequent energy transfer from the phthalate (ortho) antennae to the europium metal centre - sensitising europium(III) emission. Deprotonation of the coordinated water $\left(\mathrm{p} K_{\mathrm{a}}=8.7\right)$ leads to weaker electrostatic attraction in the ternary $\left[\mathrm{Eu}(\mathrm{CyD} 3 \mathrm{MA})\left(\mathrm{H}_{2} \mathrm{O}\right) \mathrm{OH}\right]^{2+}$ $\mathrm{pht}^{2-}$ complex, evidenced by a decrease in intensity for all $\mathrm{Eu}(\mathrm{III})$ emission bands (the Off-state). Phthalate displacement precedes hydroxycycloalkyl binding that results in the formation of the octadentate $[\mathrm{Eu}(\mathrm{CyD} 3 \mathrm{MA}) \mathrm{OH}]^{2+}$ complex, verified by the determined hydration state $(q \sim 0.5)$ at elevated $\mathrm{pH}(\mathrm{ESI}, \uparrow$ Table S3). Modulation of europium(III) emission is not observed below physiological $\mathrm{pH}$ for a buffered $[\mathrm{Eu}(\mathrm{CyD} 3 \mathrm{MA})]^{3+}$ solution that excludes KHP (ESI, $\dagger$ Fig. S8). A single $\mathrm{p} K_{\mathrm{a}}(9.0 \pm 0.1)$, determined from analysis of luminescence data (ESI, $\dagger$ Fig. S9), compares favourably with that observed for $\left[\operatorname{Eu}(\mathrm{CyD} 3 \mathrm{MA})\left(\mathrm{H}_{2} \mathrm{O}\right)\right]^{3+}\left(\mathrm{p} K_{\mathrm{a}}=\right.$ 8.7) in aqueous solution, further confirming that modulation of lanthanide emission at lower $\mathrm{pH}$ is phthalate induced.

This study identifies mixed donor octadentate europium(III) complexes as potential alternatives for $\mathrm{pH}$ dependent recognition of anions with suitable spectroscopic signatures. Spectroscopically silent octadentate europium(III) complexes are generally considered inappropriate for recognition of chelating anions. Necessary pendent donor displacement for inner-sphere coordination, potentially compromises complex stability. This work demonstrates formation of ternary outer-sphere complexes of anions, capable of sensitising europium-based emission, provides an alternative recognition event associated with changes in hydration state and ligand denticity. In particular, ortho-phthalate recognition by a mixed donor octadentate europium(III) complex, $[\mathrm{Eu}(\mathrm{CyD} 3 \mathrm{MA})]^{3+}$, is illustrated. The orthophthalate anion is shown to be an outer-sphere ligand and binding interactions result in hydration states $(q \sim 2)$ more readily associated with heptadentate chelators. Pseudo-heptadenticity is achieved by incorporating a weaker binding brachial hydroxycycloalkyl group, susceptible to dissociation upon formation of an outer-sphere ternary complex. At higher $\mathrm{pH}$ values octadenticity is restored, as determined by hydration states characteristic of octadentate europium(III) complexes, upon ortho-phthalate displacement. The above mentioned responsive nature of mixed donor, octadentate europium(III) complexes merits further investigation that may potentially impact developments in anion and molecular recognition. Observations can further contribute towards the development of analogous responsive gadolinium(mII) complexes suitable for applications in MRI imaging.

This work was supported by the University of the Witwatersrand, the National Research Foundation, and Sasol (South Africa).

\section{Notes and references}

\# DTMA $=1,4,7,10$-tetrakis $[(N$-methylcarbamyl)methyl $]$-1,4,7,10-tetraazacyclododecane; CyD3MA $=1,4,7$-tris $[(N$-methylcarbamyl $)$ methyl $]-10$ (2-hydroxy-cyclohexyl)-1,4,7,10-tetraazacyclododecane.
$\S$ Crystallographic data for (CyD3MA. $\left.\mathrm{H}_{2} \mathrm{O}\right): \mathrm{C}_{23} \mathrm{H}_{45.56} \mathrm{~N}_{7} \mathrm{O}_{4.28}, \quad M=$ 488.16, monoclinic, P21/c, $a=9.6189(2), b=32.1984(7), c=8.6632(2)$, $\alpha=90, \beta=99.5380(10)^{\circ}, \gamma=90, V=2646.02(10) \AA^{3}, Z=4, T=173(2) \mathrm{K}$, $R$ (int) 0.0288 , final full-matrix least-squares refinement converged to $R_{1}=0.0763$ (5204 reflections, $\left.F^{2}, I>2 \sigma(I)\right) ; R_{1}=0.0936$ and $\mathrm{w} R_{2}=0.1817$ for all 15521 reflections, 628 parameters, 1248 restraints, goodness-offit $(S)$ 1.143; CCDC 949568. Crystallographic data for [Eu(CyD3MA)$\left.\left(\mathrm{CF}_{3} \mathrm{SO}_{3}\right)\right]\left(\mathrm{CF}_{3} \mathrm{SO}_{3}\right)_{2}\left(\mathrm{CH}_{3} \mathrm{CN}\right)_{1.5}: \mathrm{C}_{29} \mathrm{H}_{49.5} \mathrm{EuF}_{9} \mathrm{~N}_{8.5} \mathrm{O}_{13} \mathrm{~S}_{3}, M=11444.41$, triclinic, $P \overline{1}, a=11.8523(2), b=13.4938(2), c=15.4748(3), \alpha=$ $70.5800(10)^{\circ}, \beta=70.7790(10)^{\circ}, \gamma=81.9570(10)^{\circ}, V=2202.72(7) \AA^{3}, Z=2$, $T=173(2) \mathrm{K}, R$ (int) 0.0338 , final full-matrix least-squares refinement converged to $R_{1}=0.0234$ (10631 reflections, $\left.F^{2}, I>2 \sigma(I)\right) ; R_{1}=0.0257$ and $\mathrm{w} R_{2}=0.0637$ for all 30492 reflections, 595 parameters, 0 restraints, goodness-of-fit $(S)$ 1.037; CCDC 949567.

I Spectroscopic data was acquired using Cary Eclipse Fluorescence and Cary 300 Bio UV-vis spectrometers. Hellma quartz SUPARSIL cells, path length $10 \mathrm{~mm}$, were used: type 111-QS for lifetime and phosphorescence data, type 110-QS for UV-vis data. Buffered solutions of $[\mathrm{Eu}(\mathrm{CyD} 3 \mathrm{MA})]\left(\mathrm{CF}_{3} \mathrm{SO}_{3}\right)_{3}(1.0 \mathrm{mM})$ were prepared in deionised water and $\mathrm{pH}$ adjustments performed using concentrated $\mathrm{NaOH} / \mathrm{NaOD}$ and $\mathrm{HCl} / \mathrm{DCl}$. Deprotonation constants were established using Sigmaplot programme. ${ }^{21}$ Synthesis of all compounds in ESI. $\dagger$

1 R. S. Dickins, S. Aime, A. S. Batsanov, A. Beeby, M. Botta, J. I. Bruce, J. A. K. Howard, C. S. Love, D. Parker, R. D. Peacock and H. Puschmann, J. Am. Chem. Soc., 2002, 124, 12697-12705.

2 T. Gunnlaugsson, A. J. Harte, J. P. Leonard and M. Nieuwenhuyzen, Supramol. Chem., 2003, 15, 505-519.

3 A. J. Harte, P. Jensen, S. E. Plush, P. E. Kruger and T. Gunnlaugsson, Inorg. Chem., 2006, 45, 9465-9474.

4 E. E. Hatch, J. W. Nelson, R. W. Stahlhut and T. F. Webster, Int. J. Androl., 2010, 33, 324-332.

5 J. N. Feige, L. Gelman, D. Rossi, V. Goete, R. Metivier, C. Tudor, S. I. Anghel, A. Grosdidier, C. Lathion, Y. Engelborghs, O. Michielin, W. Wahli and B. Desvergne, J. Biol. Chem., 2007, 282, 19152-19166.

6 C. Casals-Casas and B. Desvergne, Annu. Rev. Physiol., 2011, 73, 135-162.

7 A. Eveillard, F. Lasserre, M. de Tayrac, A. Polizzi, S. Claus, C. Canlet, L. Mselli-Lakhal, G. Gotardi, A. Paris, H. Guillon, P. G. P. Martin and T. Pineau, Toxicol. Appl. Pharmacol., 2009, 236, 282-292.

8 T. Fukuwatari, S. Ohsaki, S.-I. Kukuoka, R. Sasaki and K. Shibata, Toxicol. Sci., 2004, 81, 302-308.

9 B. Desvergne, J. N. Feige and C. Casals-Casas, Mol. Cell. Endocrinol., 2009, 304, 43-48.

10 A. Arbuse, C. Anda, M. A. Martinez, J. Perez-Miron, C. Jaime, T. Parella and A. Llobet, Inorg. Chem., 2007, 46, 10632-10638.

11 S. Aime, A. Barge, M. Botta, D. Parker and A. S. De Sousa, J. Am. Chem. Soc., 1997, 119, 4767-4768.

12 S. Aime, M. Botta, M. Fasano, M. P. M. Marques, C. F. G. C. Geraldes, D. Pubanz and A. E. Merbach, Inorg. Chem., 1997, 36, 2059-2068.

13 R. Carr, L. Di Bari, S. L. Piano, D. Parker, R. D. Peacock and J. M. Sanderson, Dalton Trans., 2012, 41, 13154-13158.

14 J. Hammell, L. Buttarazzi, C.-H. Huang and J. R. Morrow, Inorg. Chem., 2011, 50, 4857-4867.

15 R. M. Supkowski and W. D. Horrocks Jr., Inorg. Chim. Acta, 2002, 340, 44-48.

16 R. M. Supkowski and W. D. Horrocks Jr., Inorg. Chem., 1999, 38, 5616-5619.

17 S. Aime, A. Barge, J. I. Bruce, M. Botta, J. A. K. Howard, J. M. Moloney, D. Parker, A. S. De Sousa and M. Woods, J. Am. Chem. Soc., 1999, 121, 5762-5771.

18 D. Parker, R. S. Dickins, H. Puschmann, C. Crossland and J. A. K. Howard, Chem. Rev., 2002, 102, 1977-2010.

19 S. Aime, A. Barge, M. Botta, D. Parker and A. S. De Sousa, J. Am. Chem. Soc., 1997, 119, 4767-4768.

20 C.-H. Huang, J. Hammell, S. J. Ratnakar, A. D. Sherry and J. R. Morrow, Inorg. Chem., 2010, 49, 5963-5970.

21 Sigmaplot for windows, Version 11, Dundas Software, Germany, 1999. 